\title{
Etiologies of Dyspepsia among a Chinese Population: One Hospital-Based Study
}

\author{
Shou-Wu Lee1,2, Han-Chung Lien 1,3, Teng-Yu Lee ${ }^{1,2}$, Sheng-Shun Yang 1,3, \\ Hong-Zen Yeh ${ }^{1,3}$, Chi-Sen Chang1,2 \\ ${ }^{1}$ Division of Gastroenterology and Hepatology, Department of Internal Medicine, Taichung Veterans General \\ Hospital, Taichung, Chinese Taipei \\ ${ }^{2}$ Department of Medicine, Chung Shan Medical University, Taichung, Chinese Taipei \\ ${ }^{3}$ Department of Internal Medicine, National Yang-Ming University School of Medicine, Chinese Taipei \\ Email: ericest@vghtc.gov.tw
}

Received 15 April 2014; revised 26 May 2014; accepted 10 June 2014

Copyright ( 2014 by authors and Scientific Research Publishing Inc.

This work is licensed under the Creative Commons Attribution International License (CC BY).

http://creativecommons.org/licenses/by/4.0/

cc) (7) Open Access

\section{Abstract}

Background and Methods: Dyspepsia refers to a collection of upper gastrointestinal symptoms, and the causes may be either organic or functional. The aim of this study was to investigate the etiologies of dyspepsia among a Chinese population in Taiwan. Patients who underwent upper endoscopy for symptoms of dyspepsia were retrospectively analyzed between January and December 2008. Exclusion criteria included cirrhosis with varices, heart-burn sensation as the main symptom, gastrointestinal bleeding, hepatobiliary abnormalities, prior gastric surgery, and use of anti-acid medication for more than 2 months. Patients were classified according to the findings of upper endoscopy. Results: Data from the medical records of 2062 patients were collected and retrospectively analyzed. Normal endoscopic findings, gastritis, gastric ulcers, duodenal ulcers, reflux esophagitis and esophageal or gastric malignancy accounted for $1174(56.9 \%), 215(10.4 \%)$, $254(12.3 \%), 194(9.4 \%), 182(8.8 \%)$ and $43(2.1 \%)$ cases, respectively. The overall ratio of $H$. pylori infection was $\mathbf{2 8 . 4 \%}$. The ratio was the highest in duodenal ulcers and the lowest in reflux esophagitis. A significantly higher ratio of patients with gastric ulcers had a history of aspirin or nonsteroidal anti-inflammatory drugs (NSAIDs) usage. Conclusion: Patients with organic dyspepsia, compared to those with functional dyspepsia, were older, male, and had a higher $H$. pylori infection ratio, a positive relationship with aspirin or NSAIDs usage, and more risk factors. These findings demonstrate that upper endoscopy has a high diagnostic yield in patients in this group.

\section{Keywords}

Duodenal Ulcer, Dyspepsia, Gastric Ulcer, Gastritis, Malignancy 


\section{Background}

Dyspepsia refers to a collection of upper gastrointestinal symptoms that is believed to be commonly world-wide [1], occurring in approximately 25 percent of the population each year [2]-[4]. However, most affected people do not seek medical care due to several factors, including the severity or frequency of symptoms, fear of underlying disease, lower social class, advancing age, anxiety and lack of adequate psychological support [5]. The definition of dyspepsia that is generally accepted by most clinicians is the presence of upper abdominal pain or discomfort with or without other upper gastrointestinal symptoms, such as nausea, belching and vomiting. The causes of dyspepsia may be either organic (structural or physiological) or functional (non-organic or non-ulcer). The usual identifiable causes of the organic subgroup are peptic ulcer disease, gastro-esophageal reflux, and rarely, gastric or esophageal cancer. The definition of functional dyspepsia is the presence of "chronic or recurrent pain or discomfort centered in the upper abdomen in the absence of any known structural cause and without any features of irritable bowel syndrome" [6].

Several previous literature reviews have documented the rate of dyspepsia in Western countries, and functional dyspepsia accounted for the highest number of cases, whereas malignancy accounted for the lowest number.

However, to the best of our knowledge, no study of documented cases of dyspepsia among Chinese patients in Taiwan has been conducted. The aims of this study were to determine the prevalence of etiologies and to provide formal evidence of the empirical treatment and investigation to help primary care physicians combat dyspepsia in Chinese patients.

\section{Patients and Methods}

Data from the medical records of 2062 consecutive patients who underwent open-access upper endoscopy for symptoms of dyspepsia in our hospital, a 1155-bed academic urban tertiary-care center, were retrospectively analyzed between January 2008 and December 2008. Dyspepsia was defined as pain and discomfort centered in the upper abdomen. Exclusion criteria were as follows: [1] cirrhosis with varices or portal hypertensive gastropathy, [2] heart-burn sensation as the main symptom, [3] overt gastrointestinal bleeding, including hematemesis, tarry stool, or melena, as the major presentation, [4] chronic hepatitis, chronic pancreatitis or gallstones diagnosed by blood examination or image findings, [5] prior gastric surgery, and [6] use of anti-acid medication, such as a proton pump inhibitor (PPI) or an H2-receptor antagonist (H2RB), for more than 2 months. Written informed consent for upper endoscopy was obtained from all patients before the procedure. Use of medications, including aspirin, other nonsteroidal anti-inflammatory drugs (NSAIDs) or coumadin, was recorded. Alarm symptoms included dysphagia, poor response to short-course medications, including PPI, H2RB or gastrokinetic agents, unexplained weight loss of more than 5 kilograms in 2 months, and signs of gastrointestinal bleeding such as melena, positive fecal occult blood test, or hematemesis within the preceding month. Helicobacter pylori status was determined from antral biopsy used in the rapid urease test (CLO test, Delta West, Bentley, Australia), and testing was done at the discretion of primary gastroenterologists. Patients were classified according to the findings of upper endoscopy, which were confirmed by two experienced gastroenterologists.

Data was expressed as the standard derivation of the mean for each of the measured parameters. Gender, $H$. pylori infection, combined medication, and risk factors were expressed as percentages of the total patient number. A $p$-value below 0.05 was considered statistically significant. Statistical comparisons were made using Pearson's chi-square test to compare gender, H. pylori infection, combined medication, and risk factors; Mann-Whitney $\mathrm{U}$ test was used for analysis of the distribution of age among patient groups.

\section{Results}

Data from the medical records of 2062 consecutive patients with symptoms of dyspepsia were collected between January and December 2008 and are displayed in Table 1. Among these patients, 1174 patients (56.9\%) had normal endoscopic findings. The diagnosis of gastritis, gastric ulcers, duodenal ulcers, reflux esophagitis and esophageal or gastric malignancy, which was made by open-access upper endoscopy, accounted for 215 (10.4\%), 254 (12.3\%), 194 (9.4\%), 182 (8.8\%) and 43 (2.1\%) cases, respectively.

The distribution of age among the patients with normal endoscopic findings was 30 - 39 years, followed by those with gastritis, duodenal ulcers and reflux esophagitis (40 - 49 years) and patients with gastric ulcers and 
Table 1. Clinical characteristics of the patients with dyspepsia at admission.

\begin{tabular}{|c|c|c|c|c|c|c|c|c|c|}
\hline & & \multicolumn{8}{|c|}{ Upper Endoscopy Finding } \\
\hline & & Normal & Gastritis & GU & DU & $\begin{array}{c}\text { Reflux } \\
\text { esophagitis }\end{array}$ & Malignancy & Total & $p$-value \\
\hline \multicolumn{2}{|c|}{$\begin{array}{l}\text { Case numbers } \\
\text { (prevalence) }\end{array}$} & 1174 (56.9\%) & 215 (10.4\%) & $254(12.3 \%)$ & $194(9.4 \%)$ & $182(8.8 \%)$ & $43(2.1 \%)$ & $\begin{array}{c}2062 \\
(100 \%)\end{array}$ & \\
\hline \multicolumn{2}{|c|}{ Age (years) } & $47.36 \pm 15.43$ & $55.42 \pm 14.69$ & $60.44 \pm 15.27$ & $51.99 \pm 16.24$ & $51.87 \pm 17.99$ & $61.12 \pm 14.32$ & & $0.001 \mathrm{a}$ \\
\hline \multirow{2}{*}{ Gender } & Male & $473(40.3 \%)$ & $106(49.3 \%)$ & 142 (55.8\%) & $110(56.7 \%)$ & $116(63.7 \%)$ & 30 (69.8\%) & $\begin{array}{c}977 \\
(47.4 \%)\end{array}$ & $0.001 \mathrm{~b}$ \\
\hline & Female & $701(59.7 \%)$ & $109(50.7 \%)$ & $112(44.1 \%)$ & $84(43.3 \%)$ & $66(36.3 \%)$ & $13(30.2 \%)$ & $\begin{array}{c}1085 \\
(52.6 \%)\end{array}$ & \\
\hline \multirow{3}{*}{ H.P. } & Positive & $141(12.0 \%)$ & 75 (51.1\%) & $144(56.7 \%)$ & $111(57.2 \%)$ & $8(4.4 \%)$ & $7(16.2 \%)$ & $\begin{array}{c}438 \\
(21.2 \%)\end{array}$ & $0.001 \mathrm{~b}$ \\
\hline & Negative & $632(53.8 \%)$ & $110(34.9 \%)$ & $96(37.8 \%)$ & $73(37.6 \%)$ & $111(61 \%)$ & $30(69.8 \%)$ & $\begin{array}{c}1100 \\
(53.3 \%)\end{array}$ & \\
\hline & Not done & $401(34.2 \%)$ & $30(14 \%)$ & $14(5.5 \%)$ & $10(5.2 \%)$ & $63(34.6 \%)$ & $6(14 \%)$ & $\begin{array}{c}524 \\
(25.4 \%)\end{array}$ & \\
\hline \multirow{4}{*}{$\begin{array}{l}\text { Combined } \\
\text { medication }\end{array}$} & Nil & $1143(97.4 \%)$ & $197(91.6 \%)$ & $218(85.8 \%)$ & $187(96.4 \%)$ & 177 (97.3\%) & $42(97.7 \%)$ & $\begin{array}{c}1964 \\
(25.4 \%)\end{array}$ & \\
\hline & Aspirin & $19(1.6 \%)$ & $18(8.4 \%)$ & 19 (7.5\%) & $3(1.5 \%)$ & $4(2.2 \%)$ & $1(2.3 \%)$ & 64 (3.1\%) & $0.001 \mathrm{~b}$ \\
\hline & NSAIDs & $9(0.8 \%)$ & 0 & $15(5.9 \%)$ & $4(2.1 \%)$ & $1(0.5 \%)$ & 0 & $29(1.4 \%)$ & $0.001 \mathrm{~b}$ \\
\hline & Coumadin & $3(0.3 \%)$ & 0 & $2(0.8 \%)$ & 0 & 0 & 0 & $5(2 \%)$ & $0.384 b$ \\
\hline \multirow{5}{*}{ Risk factors } & Nil & 1105 (94.1\%) & 193 (89.8\%) & 218 (85.8\%) & 163 (84\%) & 173 (95.2\%) & 17 (39.5\%) & $\begin{array}{c}1869 \\
(90.6 \%)\end{array}$ & \\
\hline & GI bleeds & $23(2 \%)$ & $10(4.6 \%)$ & $21(8.3 \%)$ & 22 (11.3\%) & $3(1.6 \%)$ & $9(20.9 \%)$ & 88 (4.3\%) & $0.001 \mathrm{~b}$ \\
\hline & BWL & $25(2.1 \%)$ & $6(2.8 \%)$ & $9(3.5 \%)$ & $4(2.1 \%)$ & $3(1.6 \%)$ & $11(25.6 \%)$ & 58 (2.8\%) & $0.001 \mathrm{~b}$ \\
\hline & $\begin{array}{l}\text { Poor drug } \\
\text { response }\end{array}$ & $20(1.7 \%)$ & $6(2.8 \%)$ & $6(2.4 \%)$ & $5(2.6 \%)$ & $3(1.6 \%)$ & $1(2.3 \%)$ & $41(2 \%)$ & $0.630 \mathrm{~b}$ \\
\hline & Dysphagia & $1(0.1 \%)$ & 0 & 0 & 0 & 0 & $5(11.6 \%)$ & $6(3 \%)$ & $0.001 \mathrm{~b}$ \\
\hline
\end{tabular}

${ }^{\mathrm{a}}$ Kruskal-Wallis 1-Way Anova test; ${ }^{\mathrm{b}}$ Pearson’s Chi-square test ${ }^{* *}: P<0.05$; Abbreviations: BWL, body weight loss; DU, duodenal ulcers; GI, gastrointestinal; GU, gastric ulcers; H.P., Helicobacter pylori; NSAIDs: nonsteroidal anti-inflammatory drugs.

esophageal or gastric malignancy (50 - 59 years), as shown in Figure 1. We also found that more male patients had peptic ulcers, reflux esophagitis and malignancy, more female patients had normal endoscopic findings, and the numbers of male and female patients with gastritis were similar.

The ratio of $H$. pylori infection, shown in Figure 2, was highest in the patients with duodenal ulcers (60.3\%), followed by those with gastritis (40.5\%), gastric ulcers (40\%), malignancy (18.9\%), normal endoscopic findings (18.2\%) and reflux esophagitis (6.7\%).

Tracing the past medication history of the patients in our study, a significantly higher ratio of patients with gastritis (8.4\%) and gastric ulcers (7.5\%) had taken aspirin recently, and similarly, a higher proportion of patients with gastric ulcers (5.9\%) had a history of NSAIDs usage compared to the other groups. There was no significant difference of coumadin usage among patients in these five groups. As shown in Table 1, the patients with esophageal or gastric malignancy had the highest ratio of risk factors, including body weight loss, signs of gastrointestinal bleeding and dysphagia. There was no significant difference in poor response to medication.

\section{Discussion}

The definition of dyspepsia that is generally accepted by most clinicians is the presence of upper abdominal pain or discomfort with or without other upper gastrointestinal symptoms, such as nausea, belching and vomiting [1]. The precise pathophysiology of this condition remains unclear, but it is thought to result from a combination of visceral hypersensitivity, gastric motor dysfunction and psychological factors [7]. Cases of dyspepsia in previous reports were mostly caused by the functional subtype (50\% - 70\%); others were mainly caused by three major structural subtypes: peptic ulcer disease (10\%), gastro-esophageal refIux (20\%), and malignancy (2\%) [1] [8]. Our research reported a similar finding, although it was not a population-based survey. 


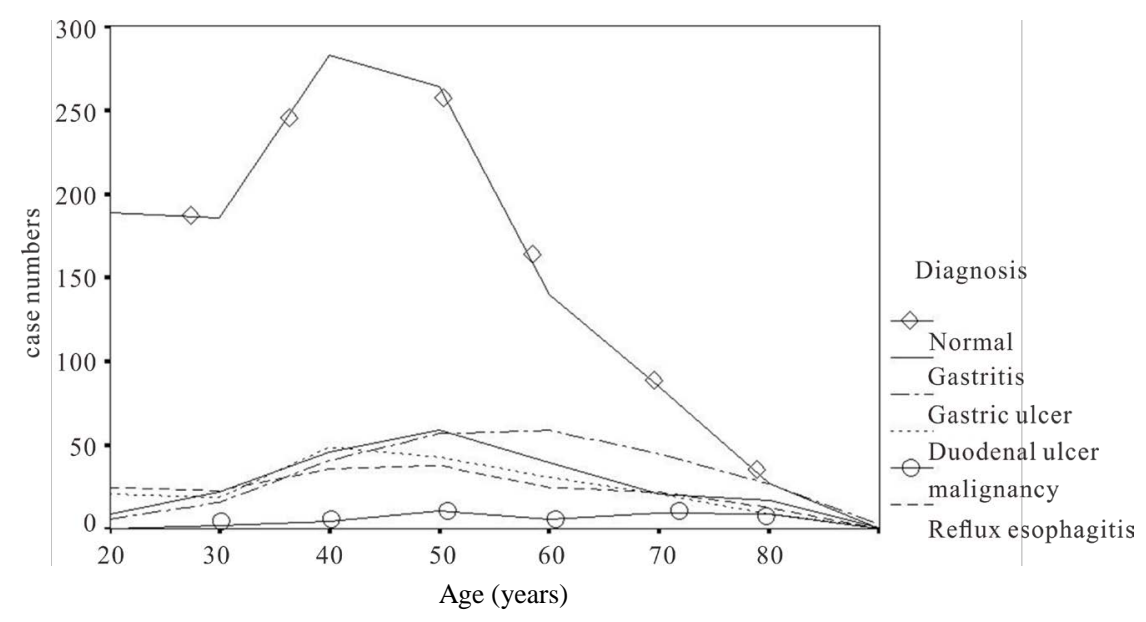

Figure 1. The distribution of age among the dyspeptic patients with different etiology.

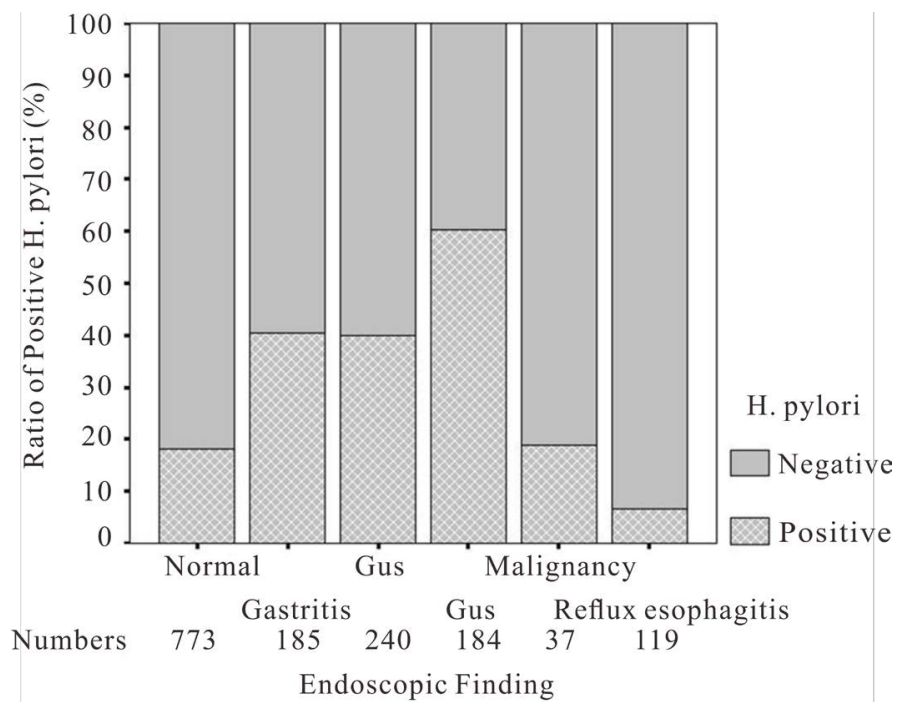

Figure 2. The ratio of $\mathrm{H}$. pylori infection among the dyspeptic patients with different etiology.

The peak prevalence of organic dyspepsia was in patients between the ages of 45 and 54 years in a Canadian survey, [9] whilst functional dyspepsia appeared to peak in Chinese subjects aged 41 - 50 years, [10] and in Japanese adults aged 50 - 59 years [11]. The average age for peak prevalence in our patients with dyspepsia was $51.0 \pm 16.4$ years. Among these patients, cases of the organic and functional type peaked at $55.8 \pm 16.4$ and 47.4 \pm 15.4 years, respectively. Patients with organic dyspepsia were significantly older than those with functional dyspepsia, implying that the diagnostic yield of upper endoscopy in patients in the former group increases with advancing age [5].

Most population-based studies have obtained relatively similar male-female ratios, and the majority of them have shown no differences in dyspepsia prevalence between genders [1]. However, some studies have noted a consistent female preponderance with functional dyspepsia [12] [13]. In a previous study of 2018 health check attendees, female gender was found to be the only independent risk factor for functional dyspepsia [14]. Similarly, our patients showed a parallel pattern, in which female predominance existed in patients with functional dyspepsia (male/female: $40.3 \% / 59.7 \%$ ) and male predominance was noted in patients with organic dyspepsia (male/female: 56.8\%/43.2\%). The male-female ratio of the overall patients with dyspepsia was similar (male/female: $47.4 \% / 52.6 \%)$.

The effect of aspirin and NSAIDs on dyspeptic symptoms has been examined specifically in some population-based studies, which concluded the regular usage of NSAIDs and aspirin is strongly associated with organic 
dyspepsia and is thought to be solely responsible for $4 \%$ of dyspepsia cases in the community [15] [16]. The results of our study provide solid evidence of the relationship between aspirin or NSAIDs usage and peptic ulcer disease, especially in patients with gastric ulcers. However, we did not find any evidence that coumadin caused symptoms of dyspepsia.

A previous population-based study investigated the association of $H$. pylori infection with dyspepsia, and it revealed $H$. pylori status to be predictive of organic dyspepsia. Furthermore, the authors concluded that $H$. pylori infection had a 5\% population-attributable risk for dyspepsia assuming a causal association [16]. Chronic gastric and duodenal ulcers are usually caused by $\mathrm{H}$. pylori (up to $70 \%$ and $95 \%$ of patients are infected, respectively, but this varies geographically). According to a previous study, between $30 \%$ and $65 \%$ of patients diagnosed with functional dyspepsia had $H$. pylori-induced gastritis [16]. However, the association between $H$. pylori and functional dyspepsia remains unclear. Our patients, with either organic or functional dyspepsia, had a lower ratio of $H$. pylori infection, and this may be because of the relatively high sanitation level in our country.

There were some limitations in our study. Firstly, our study, a form of referral-based endoscopy, as opposed to a population-based study, may be less representative of the general population due to selection bias. Secondly, there are other causes of dyspepsia which we did not take into account, such as gallstones, chronic pancreatitis, medications, metabolic disturbances and intestinal angina. Including these causes would result in overestimation of the proportion of patients with functional dyspepsia. Thirdly and fourthly, the retrospective study design and the lack of randomization, respectively, were major limitations of this study. Although the duration of this study was designed to be as long as one year, it is possible that there were unmeasured differences among these subgroups.

\section{Conclusion}

"Dyspepsia" refers to a collection of upper gastrointestinal symptoms. In this study, the prevalence of etiologies among the Chinese population in Taiwan was similar to that in previous reports. Patients with organic dyspepsia, compared to patients with functional dyspepsia, are older, male, and have a higher $H$. pylori infection ratio, a positive relationship with aspirin or NSAIDs usage, and more risk factors. These findings demonstrate that upper endoscopy has a high diagnostic yield in patients in this group.

\section{References}

[1] Mahadeva, S. and Goh, K.L. (2006) Epidemiology of Functional Dyspepsia: A Global Perspective. World Journal of Gastroenterology, 12, 2661-2666.

[2] Westbrook, J.I. and Talley, N.J. (2002) Empiric Clustering of Dyspepsia into Symptom Subgroups: A PopulationBased Study. Scandinavian Journal of Gastroenterology, 37, 917-923. http://dx.doi.org/10.1080/003655202760230874

[3] Kay, L. and Jorgensen, T. (1994) Epidemiology of Upper Dyspepsia in a Random Population. Prevalence, Incidence, Natural History, and Risk Factors. Scandinavian Journal of Gastroenterology, 29, 2-6. http://dx.doi.org/10.3109/00365529409090428

[4] Talley, N.J., Zinsmeister, A.R. and Schleck, C.D. (1992) Dyspepsia and Dyspepsia Subgroups: A Population-Based Study. Gastroenterology, 102, 1259-1268.

[5] Quadri, A. and Vakil, N. (2003) Health-Related Anxiety and the Effect of Open-Access Endoscopy in US Patients with Dyspepsia. Alimentary Pharmacology \& Therapeutics, 17, 847. http://dx.doi.org/10.1046/j.1365-2036.2003.01497.x

[6] Talley, N.J., Stanghellini, V., Heading, R.C., Kochd, K.L., Malageladae, J.R. and Tytgatf, G.N. (1999) Functional Gastroduodenal Disorders. Gut, 45, 37-42. http://dx.doi.org/10.1136/gut.45.2008.ii37

[7] Tack, J., Bisschops, R. and Sarnelli, G. (2004) Pathophysiology and Treatment of Functional Dyspepsia. Gastroenterology, 127, 1239-1255. http://dx.doi.org/10.1053/j.gastro.2004.05.030

[8] Talley, N.J., Vakil, N.B. and Moayyedi, P. (2005) American Gastroenterological Association Technical Review on the Evaluation of Dyspepsia. Gastroenterology, 129, 1756-1780. http://dx.doi.org/10.1053/j.gastro.2005.09.020

[9] Tougas, G., Chen, Y., Hwang, P., Liu, M.M. and Eggleston, A. (1999) Prevalence and Impact of Upper Gastrointestinal Symptoms in the Canadian Population: Findings from the DIGEST Study. Domestic/International Gastroenterology Surveillance Study. The American Journal of Gastroenterology, 94, 2845-2854. http://dx.doi.org/10.1111/j.1572-0241.1999.01427.x

[10] Li, Y., Nie, Y., Sha, W. and Su, H. (2002) The Link Between Psychosocial Factors and Functional Dyspepsia: An Epidemiological Study. Chinese Medical Journal, 115, 1082-1084. 
[11] Hirakawa, K., Adachi, K., Amano, K., Katsube, T., Ishihara, S., Fukuda, R., et al. (1994) Prevalence of Non-Ulcer Dyspepsia in the Japanese Population. Journal of Gastroenterology and Hepatology, 14, 1083-1087. http://dx.doi.org/10.1046/j.1440-1746.1999.02012.x

[12] Koloski, N.A., Talley, N.J. and Boyce, P.M. (2002) Epidemiology and Health Care Seeking in the Functional GI Disorders: A Population-Based Study. The American Journal of Gastroenterology, 97, 2290-2299. http://dx.doi.org/10.1111/j.1572-0241.2002.05783.x

[13] Shaib, Y. and El-Serag, H.B. (2004) The Prevalence and Risk Factors of Functional Dyspepsia in a Multiethnic Population in the United States. The American Journal of Gastroenterology, 99, 2210-2216. http://dx.doi.org/10.1111/j.1572-0241.2004.40052.x

[14] Lu, C.L., Lang, H.C., Chang, F.Y., Chen, C.Y., Luo, J.C., Wang, S.S., et al. (2005) Prevalence and Health/Social Impacts of Functional Dyspepsia in Taiwan: A Study Based on the Rome Criteria Questionnaire Survey Assisted by Endoscopic Exclusion among a Physical Check-Up Population. Scandinavian Journal of Gastroenterology, 40, 402-411. http://dx.doi.org/10.1080/00365520510012190

[15] Moayyedi, P., Forman, D., Braunholtz, D., Feltbower, R., Crocombe, W., Liptrott, M., et al. (2000) The Proportion of Upper Gastrointestinal Symptoms in the Community Associated with Helicobacter pylori, Lifestyle Factors, and Nonsteroidal Anti-Inflammatory Drugs. Leeds HELP Study Group. The American Journal of Gastroenterology, 95, 14481455. http://dx.doi.org/10.1111/j.1572-0241.2000.2126_1.x

[16] Armstrong, D. (1996) Helicobacter pylori Infection and Dyspepsia. Scandinavian Journal of Gastroenterology, 215, 38-47. http://dx.doi.org/10.3109/00365529609094532 
Scientific Research Publishing (SCIRP) is one of the largest Open Access journal publishers. It is currently publishing more than 200 open access, online, peer-reviewed journals covering a wide range of academic disciplines. SCIRP serves the worldwide academic communities and contributes to the progress and application of science with its publication.

Other selected journals from SCIRP are listed as below. Submit your manuscript to us via either submit@scirp.org or Online Submission Portal.
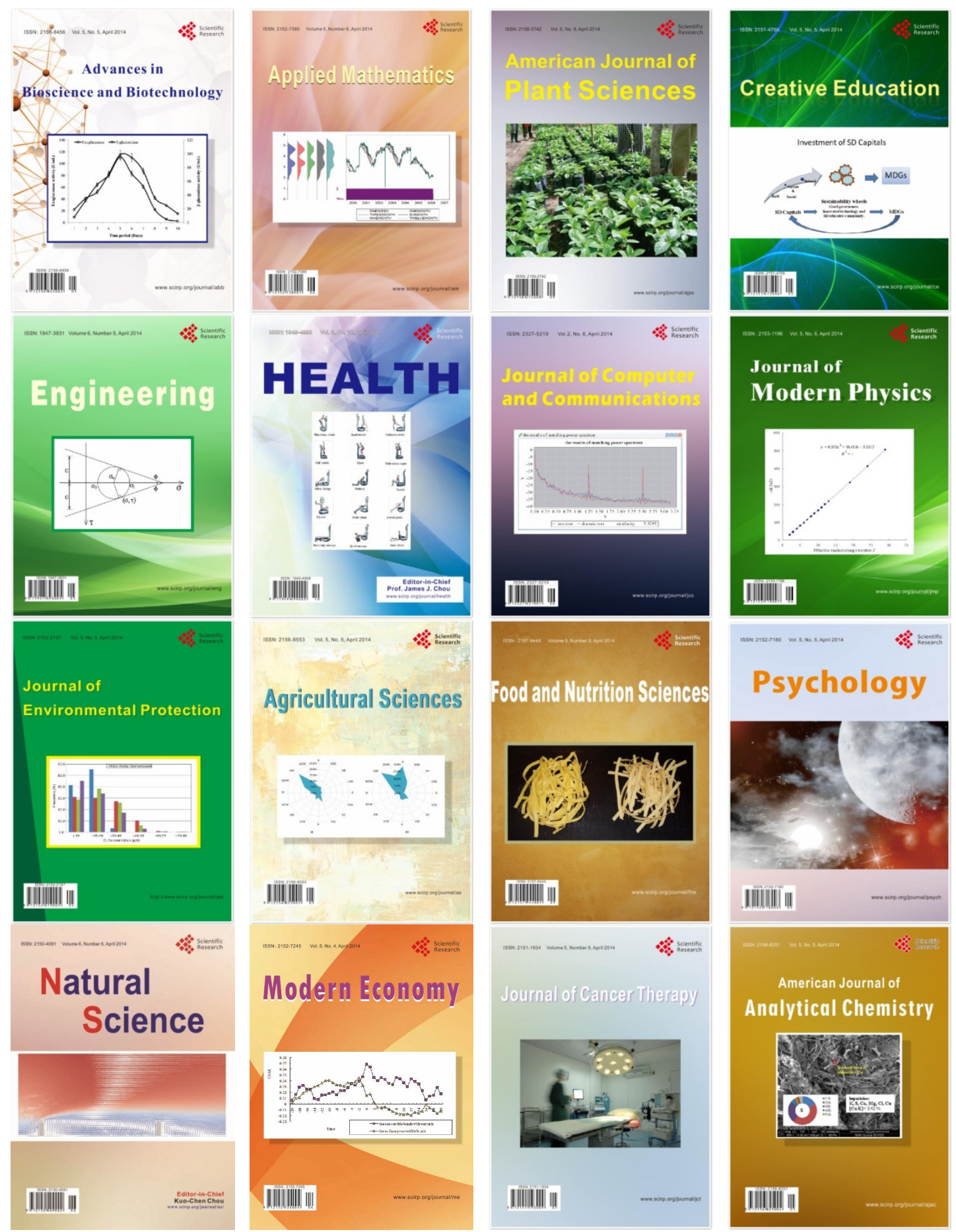